\title{
Rizóbios nativos do Rio Grande do Sul simbioticamente eficientes em Lotus glaber
}

\author{
Rhizobia native from Rio Grande do Sul simbiotically \\ efficient in Lotus glaber
}

\section{Ricardo de Albuquerque Fontoura' ${ }^{\mathrm{I}}$ Márcio Leandro dos Santos Frizzo ${ }^{\mathrm{II}}$ Enilson Luiz Saccol de SáII* Benjamin Dias Osório Filho ${ }^{\text {II }}$ Brenda Cristye Tonon ${ }^{\mathrm{II}}$ Andréia Binz $^{\mathrm{IV}}$ Marta Coutinho da Silva ${ }^{\mathrm{IV}}$ Flavio Anastácio de Oliveira Camargo ${ }^{\mathrm{III}}$ Pedro Alberto Selbach ${ }^{\mathrm{II}}$}

\section{RESUMO}

As leguminosas forrageiras, além de contribuírem para o aumento da oferta de forragem com alto teor de proteína, também são importantes como cobertura vegetal de solos. Entre as leguminosas com grande potencial forrageiro, espécies do gênero Lotus têm se destacado. Este trabalho visou à seleção de rizóbios nativos eficientes em Lotus glaber a partir de amostras de solo de cinco localidades do Rio Grande do Sul. Obtiveram-se 259 isolados de rizóbios, que foram avaliados quanto à morfologia colonial e produção de melanina. Destes, 15 isolados foram selecionados para avaliação da eficiência na fixação simbiótica de nitrogênio em experimento em casa de vegetação e caracterizados geneticamente por comparação do perfil eletroforético dos produtos de amplificação do DNA genômico, por PCR com os oligonucleotídeos iniciadores BOX e ERIC. Apenas cinco isolados produziram melanina. Nove isolados foram mais eficientes do que a estirpe SEMIA 830, que é autorizada para a produção de inoculante para L. glaber no país. Na caracterização genética, observou-se que nenhum isolado apresentou identidade com as estirpes recomendadas, o que demonstra que, nos solos do Rio Grande do Sul, existem rizóbios autóctones eficientes na fixação simbiótica de nitrogênio com L. glaber, podendo ser recomendados para estudos a campo, visando a uma futura produção de inoculantes para estas leguminosas no Brasil.

Palavras-chave: fixação simbiótica do nitrogênio, leguminosas forrageiras, inoculante, Lotus glaber.

\section{ABSTRACT}

Forage legumes besides contributing to increase the supply of high protein content forage are also good cover for the soil surface. Among the legumes with high potential forage, the genus Lotus has been outstanding. This research aimed to selectnative rhizobia efficient in fixing nitrogen with Lotus glaber, from soil samples of five localities of Rio Grande do Sul. A total of 259 rhizobia isolates were obtained, which were evaluated based on colony morphology and in vitro melanin production. Among them, 15 isolates were selected for the evaluation of the symbiotic nitrogen fixation efficiency in greenhouse experiments and genetically characterized by genomic DNA fingerprinting, PCR amplification with BOX and ERIC primers. Only five isolates produced melanin. Nine isolates were more efficient than strain SEMIA 830, which is authorized for the production of commercial inoculants of $\boldsymbol{L}$. glaber in Brazil. In relation to the genetic characterization, the isolates have shown no similarity with the commercial strains, indicating that in the soils of Rio Grande do Sul there are autochthonous rhizobia capable of efficient symbiotic nitrogen fixation with L. glaber, which might be recommended for field evaluations, aiming a future production of inoculants for this legume in Brazil.

Key words: forrage legumes, inoculante, Lotus glaber, symbiotic nitrogen fixation.

\section{INTRODUÇÃO}

A utilização de leguminosas forrageiras inoculadas com rizóbios eficientes na fixação de nitrogênio contribui para o aumento da oferta de forragem com alto teor de proteína, principalmente em solos de pouca produtividade, bem como em campos nativos. No Brasil, Lotus glaber é uma leguminosa

'Programa de Pós-graduação em Microbiologia Agrícola e do Ambiente, Universidade Federal do Rio Grande do Sul (UFRGS), Porto Alegre, RS, Brasil.

"Programa de Pós-graduação em Ciência do Solo, UFRGS, Porto Alegre, RS, Brasil.

"I'Departamento de Solos, UFRGS, 91540-000, Porto Alegre, RS, Brasil. E-mail: enilson.sa@ ufrgs.br. *Autor para correspondência.

${ }^{\mathrm{IV}}$ Curso de Agronomia, UFRGS, Porto Alegre, RS, Brasil. 
introduzida com boa adaptabilidade às condições do Rio Grande do Sul, podendo ser uma alternativa para o uso em solos com limitações. É uma planta que se adapta bem a ambientes úmidos de clima temperado (BLUMENTHAL \& MCGRAW, 1999), como solos de áreas arrozeiras. Tem bom crescimento em campo alagado na região centro-oeste da Argentina, crescimento ótimo no outono e na primavera, e tolera baixas temperaturas e cobertura de gelo (VIGNOLIO et al., 1999) e ambientes de muita salinidade. MUJICA \& RUMI (1999) constataram boa resistência à salinidade na germinação de sementes de duas variedades de $\boldsymbol{L}$. glaber oriundas da bacia do Rio Salado, Argentina, região também conhecida por solos com $\mathrm{pH}$ elevado. No Chile, essa espécie cresce espontaneamente nas áreas arrozeiras, está presente nas pastagens da zona central do país e tem uma contribuição importante na produção forrageira, especialmente durante a temporada estival, em solos argilosos que eventualmente recebem água de irrigação (BARRIENTOS et al., 2002).

O principal grupo de rizóbios eficientes em simbiose com $\boldsymbol{L}$. glaber é o do gênero Mesorhizobium (Mesorhizobium loti), mesmo grupo de simbiontes em plantas de L. corniculatus (IRISARRI et al., 1996; BARAIBAR et al. 1999; LABANDERA, 2007). São bactérias de crescimento rápido e de alta produção de goma em meio com manitol como única fonte de carbono. No entanto, $\boldsymbol{L}$. glaber pode formar simbiose com outros rizóbios, podendo desenvolver nódulos ineficientes na fixação de nitrogênio (IRISARRI et al., 1996), e afetar a produção. Este trabalho visou à seleção de rizóbios nativos de solos do Rio Grande do Sul, eficientes na fixação de nitrogênio em simbiose com plantas de L. glaber.

\section{MATERIAL E MÉTODOS}

As amostras de solo foram coletadas em Bagé (coordenadas geográficas $31^{\circ} 18^{\prime} 42.22^{\prime \prime} \mathrm{S} ; 54^{\circ}$ 0'59.14"O), Eldorado do Sul (30 6'3.05"S; $\left.51^{\circ} 41^{\prime} 29.19^{\prime \prime O}\right)$, Passo Fundo (28 13'26.12"S; $\left.52^{\circ} 23^{\prime} 45.69^{\prime \prime} \mathrm{O}\right)$, Porto Alegre ( $30^{\circ} 4^{\prime} 9.15^{\prime \prime} \mathrm{S} ; 51^{\circ}$ $\left.8^{\prime} 35.51^{\prime \prime O}\right)$ e Rio Pardo (29॰59'8.93"S - 52 25'32.63"O) e acondicionadas em sacos plásticos, identificadas e mantidas à temperatura ambiente para transporte até o laboratório. Amostras de plantas de diferentes espécies de Lotus foram coletadas em Mostardas e Porto Alegre. $\mathrm{O}$ isolamento de rizóbios a partir das amostras de solo ocorreu em prazo máximo de uma semana e, a partir dos nódulos coletados no campo, em 24 horas após a coleta, uma vez que eles não foram conservados em sílica. Para a obtenção de nódulos, sementes de Lotus glaber
Mill. (=Lotus tenuis Waldst. et Kit. ex Wild.) (cedidas pelo Dr. DAL'AGNOLL) foram desinfestadas superficialmente por imersão em etanol (70\%) por 30s, hipoclorito de sódio $(5 \%)$ por $1 \mathrm{~min}$ e lavadas sete vezes seguidas em água destilada esterilizada. A seguir, as sementes foram colocadas para germinar em papel filtro esterilizado, em estufa a $28^{\circ} \mathrm{C}$, por 24 horas. Os vasos utilizados foram do tipo Leonard com mistura de vermiculita e areia (na proporção de 2:1) na parte superior, esterilizados em autoclave a $120^{\circ} \mathrm{C}$ por $90 \mathrm{~min}$, e adicionando-se, na parte inferior, solução nutritiva de SARRUGE (1975) sem nitrogênio. As plântulas foram colocadas nos vasos e inoculadas com $10 \mathrm{ml}$ da suspensão de $10 \mathrm{~g}$ de solo em $90 \mathrm{ml}$ de solução salina ( $\mathrm{NaCl} 0,85 \%)$ esterilizada. Cada amostra de solo foi inoculada em dois vasos, com duas plantas cada, as quais foram cultivadas em casa de vegetação por 30 dias a partir da inoculação. Os nódulos obtidos foram desinfestados superficialmente, conforme método descrito acima para desinfestação das sementes, e macerados com pinça esterilizada sobre placas de Petri com meio extrato-de-levedura manitol sólido (LM) com vermelho congo (LMV) (VINCENT, 1970). As colônias obtidas foram isoladas e purificadas por inoculação em placas com LMV até a obtenção de colônias homogêneas e com características persistentes. Os isolados foram inoculados em tubos de ensaio com LM ágar inclinado e mantidos em criopreservação a $80^{\circ} \mathrm{C} \mathrm{em}$ tubos de microcentrífuga com LM-Glicerol 50\% (v:v). As plantas de Lotus coletadas a campo tiveram seus nódulos destacados, lavados e desinfestados superficialmente, procedendo-se ao isolamento conforme metodologia descrita acima.

A produção de melanina dos isolados foi avaliada conforme o método de CUBO et al. (1988). Como controles positivos, foram utilizados os isolados 7E e 1AG, rizóbios nativos isolados de solos de São Paulo (SÁ, 2001).

A eficiência da fixação simbiótica do nitrogênio pelos isolados de rizóbios nativos foi avaliada em experimento com vasos do tipo Leonard, confeccionados conforme descrito anteriormente, com delineamento experimental em blocos ao acaso. As sementes foram desinfestadas superficialmente, prégerminadas por 24 horas, conforme descrito anteriormente, e plantadas nos vasos. Após o plantio, foi realizada a inoculação com alíquotas de $5 \mathrm{ml}$ da suspensão de cada cultura de rizóbio, crescida em meio LM líquido, com cerca de $10^{8} \mathrm{ufc} \mathrm{mL}^{-1}$. Foram estudados 18 tratamentos inoculados com a estirpe SEMIA 830, fornecida pela coleção de culturas da FEPAGRO, e a estirpe U510, do Uruguai, (fornecida pelo Dr. Labandera), além dos isolados UFRGS Lg4, UFRGS 
Lg9, UFRGS Lg13, UFRGS Lg108, UFRGS Lg19, UFRGS Lg29, UFRGS Lg30, UFRGS Lg113, UFRGS Lg119, UFRGS Lg121, UFRGS Lg124, UFRGS Lg138, UFRGS Lg144, UFRGS Lg149, UFRGS Lg156 e UFRGS Lg166. Além dos tratamentos com plantas inoculadas, foram incluídos dois tratamentos controle sem inoculação, um com adição de solução de $\mathrm{NH}_{4} \mathrm{NO}_{3}$ (equivalente a $100 \mathrm{~kg}$ de $\mathrm{N} \mathrm{ha}^{-1}$ ) aplicada duas vezes por semana, ao longo do experimento e o outro sem nitrogênio.

Após 97 dias, a parte aérea das plantas foi cortada e colocada em sacos de papel e os nódulos retirados da raiz, contados e colocados em sacos de papel para secagem em estufa a $60^{\circ} \mathrm{C}$, com aeração forçada, até atingir peso constante. A seguir, determinou-se a massa seca da parte aérea e dos nódulos em balança digital semi-analítica. $\mathrm{O}$ teor de nitrogênio total foi determinado pelo método semi micro Kjeldahl (TEDESCO et al., 1995). A análise estatística dos dados foi realizada pela comparação de médias pelo teste de SCOTT-KNOTT (1974) a $1 \%$ de significância e determinou-se o índice de eficiência relativa (BROCKWELL et al., 1966).

Para a caracterização genética dos isolados de rizóbios nativos, o DNA genômico foi extraído usando-se o procedimento descrito por SÁ (2001). No procedimento empregado, foram utilizadas quantidades reduzidas de SDS e perclorato de sódio, e solução de clorofórmio-álcool isoamílico para a precipitação de proteínas e impurezas e o emprego de sílica para separação do DNA. O produto da extração foi mantido em freezer a $-20^{\circ} \mathrm{C}$ até o momento das análises. ODNA genômico dos isolados e das estirpes foi amplificado usando-se os nucleotídeos iniciadores ERIC (DE BRUIJN, 1992) e BOX A1 (VERSALOVIC et al., 1994). As reações foram realizadas de acordo com o protocolo descrito por RICHARDSON et al. (1995) modificado, sendo usada a temperatura de anelamento de $51^{\circ} \mathrm{C}$ para reações com o oligonucleotídeo ERIC e $53^{\circ} \mathrm{C}$ para BOX.

Os produtos de amplificação foram submetidos à eletroforese em gel de agarose a 1,5\% em tampão TBE $1 \mathrm{x}$ por três horas a $80 \mathrm{~V}$. O perfil de bandas no gel foi transformado em uma matriz binária bidimensional, pelo programa GelPro Analyser 3.1. A similaridade/dissimilaridade genética entre os isolados foi avaliada pelo coeficiente de JACCARD $(i, j)$. As matrizes foram analisadas em conjunto pelo programa NTSYS-PC 2.01a (1997) e os dendrogramas obtidos pelo método de agrupamento UPGMA (Unweighted Pair Group Method with Arithmetic Averages) pelo programa SAHN CLUSTERING do NTSYS. O índice de SHANNON-WEAVER (1948) para a diversidade dos isolados foi calculado usando-se a fórmula $\mathrm{H}=\mathrm{C}$ / $\mathrm{N}\left(\mathrm{N} x \log \mathrm{N}-\sum \mathrm{ni} x \log \mathrm{ni}\right)$, onde o ni corresponde ao número dos isolados com o mesmo perfil para o PCR dos dois oligonucleotídeos, $\mathrm{N}$ corresponde ao número total dos isolados e C é uma constante igual a 2,3.

\section{RESULTADOS E DISCUSSÃO}

Foram obtidos 259 isolados de rizóbios a partir de nódulos de $\boldsymbol{L}$. glaber, em cinco das oito amostras de solo estudadas, sendo 35 isolados nas amostras de solo de Bagé, 18 de Eldorado do Sul, 107 de Passo Fundo, 29 de Porto Alegre e 70 de Rio Pardo. Embora o cultivo de L. glaber não seja expressivo no estado, o grande número de isolados obtidos para esta espécie pode estar relacionado ao fato de que os rizóbios capazes de estabelecer simbiose com Lotus corniculatus também são capazes de nodular $L$. glaber (BARAIBAR et al., 1999; LABANDERA, 2007), formando um grupo de inoculação cruzada. Deve-se salientar que as amostras de solo provenientes de Eldorado do Sul, Passo Fundo e Porto Alegre correspondem a áreas experimentais onde têm sido cultivadas diversas espécies de Lotus e outras leguminosas forrageiras. Dessa forma, os isolados de rizóbios capazes de nodular $\boldsymbol{L}$. glaber podem não ser originados de população microbiana autóctone e sim de população introduzida. Porém, tal possibilidade não explica o fato de que em áreas sem histórico de cultivo anterior com Lotus, foram obtidos rizóbios capazes de nodular essa espécie, sendo possível que estes rizóbios sejam autóctones. No entanto, esse fato não invalida trabalhos de seleção de estirpes mais eficientes a partir de população de rizóbios já adaptadas às condições de tais solos.

Os nódulos obtidos de plantas de $\boldsymbol{L}$. glaber possuíam tamanho de 1 a $5 \mathrm{~mm}$ e coloração interna verde ou vermelha. Esta observação foi mais evidente em plantas inoculadas com amostra de solo de Bagé, que apresentaram nódulos de diversos tamanhos e colorações na mesma planta, o que poderia indicar a nodulação por rizóbios diferentes.

Todos os isolados obtidos foram caracterizados quanto à morfologia das colônias. Os rizóbios estudados quanto à eficiência em $\boldsymbol{L}$. glaber apresentaram colônias de $4 \mathrm{~mm}$ a mais de $10 \mathrm{~mm}$ de diâmetro e muita produção de goma, com cerca de 5 a 7 dias de crescimento em placas com meio LMA. Essas características são comumente observadas em colônias de estirpes do gênero Mesorhizobium e Rhizobium (BARBERI et. al., 1998; WANG et al., 2003). Já os isolados UFRGS Lg30, Lg121 e Lg138 apresentaram crescimento lento e colônias pequenas com pouca produção de goma, semelhantes às características de colônias de Bradyrhizobium elkani. Observações 
semelhantes foram obtidas nos trabalhos de BARAIBAR et al. (1999) e LABANDERA (2007), e as características dos isolados obtidos em L. glaber sugerem que esta espécie pode ser nodulada tanto por bactérias do gênero Mesorhizobium, como do gênero Bradyrhizobium.

A capacidade para produção de melanina foi observada apenas nos isolados UFRGS Lg111, Lg121, Lg124, Lg125 e Lg128, todos oriundos de amostra de solo de Porto Alegre. Neste trabalho, observou-se que a produção de melanina não parece ser uma capacidade muito difundida entre os isolados de rizóbios estudados, não sendo uma característica útil, no caso deste trabalho, para a diferenciação entre isolados, uma vez que apenas cinco isolados foram capazes de produzir melanina. A formação de melanina poderia estar relacionada à proteção contra estresses ambientais, principalmente compostos fenólicos originados da degradação da matéria orgânica do solo ou da senescência do nódulo (BORTHAKUR et al., 1987). GIONGO et al. (2006) observaram que os solos de onde foram isolados rizóbios sem esta característica fenotípica apresentavam baixo teor de matéria orgânica. Por outro lado, a produção de melanina foi observada em rizóbios nativos, capazes de nodular feijoeiro, de solo da região de CUNHA - SP, sujeito a inundações periódicas e com maior teor de matéria orgânica (SÁ, 2001).

$\mathrm{Na}$ avaliação da eficiência simbiótica, os isolados de rizóbios estudados, que haviam sido previamente selecionados para ensaio de eficiência em experimento em tubos (dados não mostrados), bem como as estirpes SEMIA 830 e U510, induziram nodulação e fixaram nitrogênio em simbiose com plantas de $\boldsymbol{L}$. glaber em condições de casa de vegetação. As plantas inoculadas com os isolados UFRGS Lg149, Lg19, Lg144, Lg30, Lg13, Lg121, Lg9 e Lg4 produziram o maior número de nódulos (até 203) por planta, sendo superiores ao das plantas inoculadas com as estirpes SEMIA 830 e U510, enquanto que as inoculadas com o isolado UFRGS Lg113 apresentaram o menor número de nódulos (43 nódulos. Planta-1 ${ }^{-1}$ (Tabela 1). Todas as plantas que produziram elevado número de nódulos também apresentaram massa de nódulos superior à formada nas plantas dos demais tratamentos (Tabela 1), exceto as inoculadas com os isolados UFRGS Lg166, Lg108 e com a estirpe U510 que, embora tenham apresentado elevada massa de nódulos, não

Tabela 1 - Nitrogênio total, massa seca da parte aérea, massa seca dos nódulos, número de nódulos formados por plantas de $\boldsymbol{L}$. glaber inoculadas e índice de eficiência relativa na fixação simbiótica de nitrogênio com os isolados de rizóbios estudados e com as estirpes SEMIA 830 e U510 (médias de 4 repetições).

\begin{tabular}{|c|c|c|c|c|c|}
\hline Tratamento & $\begin{array}{l}\text { Nitrogênio total } \\
\left(\mathrm{mg} \mathrm{planta}^{-1}\right)\end{array}$ & $\begin{array}{l}\text { Massa seca da parte } \\
\left.\text { aérea (mg. planta }{ }^{-1}\right)\end{array}$ & $\begin{array}{l}\text { Massa seca dos } \\
\text { nódulos }\left(\mathrm{mg} \mathrm{planta}^{-1}\right)\end{array}$ & $\begin{array}{l}\text { Número de nódulos } \\
\text { planta }^{-1}\end{array}$ & $\begin{array}{c}\text { Índice de eficiência } \\
\text { relativa }(\%)\end{array}$ \\
\hline $\mathrm{T}+\mathrm{N}$ & $29,5 \mathrm{a}$ & $2.380 \mathrm{a}$ & - & - & $100,0 \mathrm{a}$ \\
\hline UFRGS Lg30 & $39,1 \mathrm{a}$ & $1.413 \mathrm{~b}$ & $112,0 \mathrm{a}$ & $186 \mathrm{a}$ & $132,7 \mathrm{a}$ \\
\hline UFRGS Lg121 & $28,2 \mathrm{a}$ & $1.303 \mathrm{~b}$ & $147,1 \mathrm{a}$ & $178 \mathrm{a}$ & $95,5 \mathrm{a}$ \\
\hline UFRGS Lg19 & $33,4 \mathrm{a}$ & $1.218 \mathrm{~b}$ & $115,3 \mathrm{a}$ & $200 \mathrm{a}$ & 79,3 a \\
\hline UFRGS Lg149 & $30,7 \mathrm{a}$ & $1.173 \mathrm{~b}$ & $144,0 \mathrm{a}$ & $203 \mathrm{a}$ & $108,6 \mathrm{a}$ \\
\hline UFRGS Lg144 & $25,7 \mathrm{a}$ & $1.153 \mathrm{~b}$ & $134,4 \mathrm{a}$ & $195 \mathrm{a}$ & $87,1 \mathrm{a}$ \\
\hline UFRGS Lg108 & $30,5 \mathrm{a}$ & $1.128 \mathrm{~b}$ & $121,1 \mathrm{a}$ & $111 \mathrm{~b}$ & $103,3 \mathrm{a}$ \\
\hline UFRGS Lg9 & $28,1 \mathrm{a}$ & $1.123 \mathrm{~b}$ & $143,5 \mathrm{a}$ & $166 \mathrm{a}$ & $95,2 \mathrm{a}$ \\
\hline UFRGS Lg166 & $26,7 \mathrm{a}$ & $1.053 \mathrm{~b}$ & $124,3 \mathrm{a}$ & $135 \mathrm{~b}$ & $77,6 \mathrm{a}$ \\
\hline UFRGS Lg4 & $27,6 \mathrm{a}$ & $953 \mathrm{~b}$ & $108,0 \mathrm{a}$ & $146 \mathrm{a}$ & $93,2 \mathrm{a}$ \\
\hline U510 & $18,2 \mathrm{~b}$ & $733 \mathrm{c}$ & $116,6 \mathrm{a}$ & $125 \mathrm{~b}$ & $61,1 \mathrm{~b}$ \\
\hline UFRGS Lg156 & $16,9 \mathrm{~b}$ & $690 \mathrm{c}$ & $93,0 \mathrm{~b}$ & $114 \mathrm{~b}$ & $56,4 \mathrm{~b}$ \\
\hline UFRGS Lg138 & $18,9 \mathrm{~b}$ & $655 \mathrm{c}$ & $93,3 \mathrm{~b}$ & $95 \mathrm{~b}$ & $63,6 \mathrm{~b}$ \\
\hline UFRGS Lg13 & $11,2 \mathrm{~b}$ & $573 \mathrm{c}$ & $85,3 \mathrm{~b}$ & $180 \mathrm{a}$ & $37,1 \mathrm{~b}$ \\
\hline UFRGS Lg29 & $17,4 \mathrm{~b}$ & $525 \mathrm{c}$ & $73,4 \mathrm{~b}$ & $112 b$ & $58,3 \mathrm{~b}$ \\
\hline SEMIA 830 & $15,0 \mathrm{~b}$ & $500 \mathrm{c}$ & $72,0 \mathrm{~b}$ & $98 \mathrm{~b}$ & $64,5 \mathrm{~b}$ \\
\hline UFRGS Lg113 & $12,4 \mathrm{~b}$ & $500 \mathrm{c}$ & $55,4 \mathrm{~b}$ & $43 c$ & $41,2 \mathrm{~b}$ \\
\hline UFRGS Lg124 & $10,4 \mathrm{~b}$ & $440 \mathrm{c}$ & $66,3 \mathrm{~b}$ & $107 \mathrm{~b}$ & $34,6 \mathrm{~b}$ \\
\hline UFRGS Lg119 & $7,2 \mathrm{c}$ & $308 \mathrm{c}$ & $59,1 \mathrm{~b}$ & $103 \mathrm{~b}$ & $23,5 \mathrm{~b}$ \\
\hline $\mathrm{T}-\mathrm{N}$ & $0,4 \mathrm{c}$ & $35 \mathrm{c}$ & - & - & - \\
\hline
\end{tabular}

Valores seguidos por letras iguais na coluna não diferem significativamente pelo teste de Scott-Knott a 1\% de significância. Legenda: $\mathrm{T}+\mathrm{N}=$ controle sem inoculação e com adição de nitrogênio; T-N= controle sem inoculação e sem adição de nitrogênio. 
apresentaram elevado número de nódulos, indicando a formação de nódulos maiores e mais pesados. Observa-se ainda que, em relação à massa de nódulos formados, o tratamento inoculado com a estirpe U510 foi superior ao inoculado com a estirpe SEMIA 830, embora não tenham diferido no número de nódulos (Tabela 1).

Os isolados obtidos neste trabalho apresentaram grande capacidade de induzir nodulação em L. glaber (sendo a maior média de 203 nódulos planta $^{-1}$ produzidos pelo isolado UFRG Lg149)), quando comparados com os dados obtidos por BARRIENTOS et al. (2002), com 68 cepas autóctones de regiões do Chile, onde apenas 11 cepas induziram a formação de nódulos, sendo a maior nodulação de 10 nódulos por planta.

As plantas controle, sem inoculação e com adição de nitrogênio, produziram maior massa seca na parte aérea (Tabela 1). Já as inoculadas com os isolados UFRGS Lg30, Lg19, Lg9 e Lg4, oriundos de Rio Pardo, Lg121 e Lg108, de Porto Alegre e Lg149, Lg144 e Lg166, de Passo Fundo, produziram massa seca da parte aérea superior à das inoculadas com as estirpes SEMIA 830 e U510 e com os demais isolados (Tabela 1).

As plantas inoculadas com os isolados UFRGS Lg30, Lg19, Lg149, Lg108, Lg121, Lg9, Lg4, Lg166 e Lg144 acumularam maior teor de nitrogênio fixado na parte aérea (Tabela 1), não diferindo das plantas do tratamento controle sem inoculação e com adição de nitrogênio, mas foram superiores às plantas inoculadas com as estirpes SEMIA 830 e U510, que não diferiram entre si. Os isolados UFRGS Lg30, Lg19, Lg149 e Lg108 apresentaram, respectivamente, "Índice de Eficiência Relativa” de 133, 113, 104 e 103\% (Tabela 1), superiores aos índices das estirpes SEMIA 830 e U510, respectivamente, 50 e $61 \%$. Esses isolados mostraramse muito eficientes na fixação simbiótica de nitrogênio, pois forneceram esse nutriente para a planta em teor superior e/ou equivalente ao fornecido com a suplementação mineral via solução nutritiva. Assim, esses isolados foram mais eficientes na simbiose com plantas de $\boldsymbol{L}$. glaber, em condições de casa de vegetação, do que a estirpe SEMIA 830, atualmente recomendada para esta espécie no Brasil, podendo ser usados, após confirmação do desempenho superior em ensaios a campo, como estirpes recomendadas. Em estudo com cepas para $\boldsymbol{L}$. glaber (BARRIENTOS et al., 2002), foram obtidos dados semelhantes, no qual o teor de nitrogênio total na parte aérea de plantas inoculadas com três cepas foi superior ao do controle com adição de nitrogênio, embora apresentassem baixo número de nódulos em plantas de L.glaber cultivadas por 45 dias.

Já as plantas inoculadas com o isolado UFRGS Lg 119 apresentaram o menor teor de nitrogênio fixado, não diferindo das plantas do tratamento controle não inoculado e sem adição de nitrogênio, o que demonstra que este isolado, embora não apresente problemas em induzir nodulação, produzindo número de nódulos similar ao das estirpes SEMIA 830 e U510 (Tabela 1), é ineficiente na fixação simbiótica de nitrogênio. No entanto, o Índice de Eficiência Relativa (23\%) obtido por este isolado (Tabela 1), embora baixo, não diferiu dos índices obtidos pelas estirpes SEMIA 830 e U510 e pelos isolados UFRGS Lg138, Lg29, Lg156, Lg113, Lg13 e Lg124, comparados pelo teste de ScottKnott a $1 \%$ de probabilidade de erro.

No dendrograma, o qual foi obtido pelo agrupamento dos perfis de fragmentos de DNA dos isolados de rizóbios e estirpes para $L$. glaber amplificados com os oligonucleotídeos iniciadores BOXA1 e ERIC (Figura 1), o isolado UFRGS Lg113, oriundo da amostra de solo de Porto Alegre, de uma área experimental onde se tem histórico de inoculação frequente com diferentes estirpes, destaca-se com apenas $25 \%$ de similaridade com os demais rizóbios estudados. Também se observa que os isolados estudados não mostraram grande similaridade com as estirpes U510 e SEMIA 830. Na análise e agrupamento conjunto do perfil de fragmentos de DNA, obtido com os oligonucleotídeos iniciadores BOXA1 e ERIC, os isolados UFRGS Lg138, Lg166, Lg144 e Lg156, todos oriundos de amostra de solo de Passo Fundo, e os isolados UFRGS Lg 19 e Lg 29, obtidos da amostra de Rio Pardo, mostraram similaridade total (100\%). Apesar dessa similaridade, os índices de eficiência relativa na fixação simbiótica de nitrogênio (Tabela 1) indicam que os isolados UFRGS Lg166 e Lg144 são diferentes dos isolados UFRGS Lg138 e Lg156. O mesmo pode ser observado com o isolado UFRGS Lg19, que apresentou índice de eficiência relativa de $115 \%$, e o isolado UFRGS Lg29, com 59\%. Isso pode ser explicado pelo fato de os oligonucleotídeos iniciadores utilizados (BOX A1 e ERIC) amplificam regiões intergênicas repetidas e conservadas do genoma (DE BRUIJN, 1992; VERSALOVIC et al., 1994), apresentando distribuição aleatória no genoma, e não amplificam os genes relacionados à fixação biológica do nitrogênio. Dessa forma, a similaridade observada nos perfis eletroforéticos dos fragmentos da amplificação não implica similaridade de genes de nodulação e fixação do nitrogênio.

Entre os isolados com índice de eficiência relativa superior a 80\% (Tabela 1), UFRGS Lg30, Lg121 e Lg108, a análise dos perfis eletroforéticos da PCR com BOX A1 e ERIC mostrou que estes apresentaram menos de $40 \%$ de similaridade entre si e apenas $30 \%$ de similaridade com as estirpes SEMIA830 e U510 (Figura 1). 


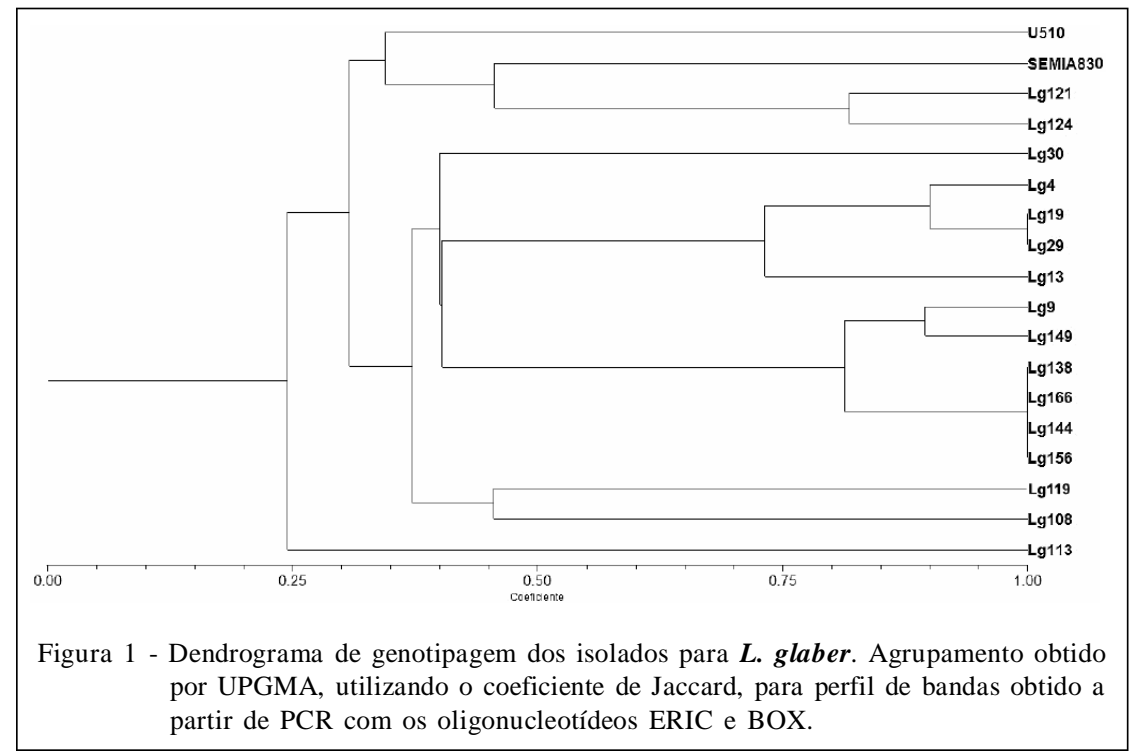

Tais resultados indicam que esses isolados eficientes não são re-isolamentos das estirpes recomendadas. Não foi observada identidade total entre isolados obtidos de localidades diferentes. Os fragmentos de DNA, obtidos pela PCR com oligonucleotídeos iniciadores como BOX, ERIC e REP, permitem a diferenciação das estirpes de rizóbios (VERSALOVIC et al., 1994; de BRUIJN, 1992; SÁ, 2001; MOSTASSO et al., 2002; GIONGO et al., 2003), ou até variantes de estirpes (CHUEIRE et al., 2000, CARVALHO, 2003). Neste trabalho, essa técnica se mostrou eficiente na avaliação da diversidade genética dos rizóbios autóctones estudados.

O índice de diversidade de Shannon (SHANNON \& WEAVER, 1948), para os rizóbios isolados de $\boldsymbol{L}$. glaber, avaliados quanto ao perfil eletroforético da PCR, obtidos com os oligonucleotídeos BOXA1 e ERIC, foi estimado em 2,098. Esses resultados se assemelham aos obtidos por GRANGE (2005), com rizóbios isolados de feijoeiro (Phaseolus vulgaris) em três áreas distintas do cerrado (cultivadas com leguminosas, sem leguminosas e não cultivadas), em que, para o oligonucleotídeo BOX, também foram obtidos elevados índices de diversidade de Shannon.

\section{CONCLUSÃO}

Conclui-se que: a) nos solos do Rio Grande do Sul existem rizóbios nativos capazes de formar nódulos e fixar nitrogênio em $\boldsymbol{L}$. glaber; b) existem rizóbios nativos mais eficientes na fixação simbiótica de nitrogênio em $\boldsymbol{L}$. glaber do que a estirpe recomendada SEMIA 830, sendo eles os isolados UFRGS Lg30, Lg19, Lg149, Lg108, Lg121, Lg9, Lg4, Lg166 e Lg144; c) os isolados de rizóbios para L. glaber estudados diferem da estirpe SEMIA 830, usada na produção de inoculantes para esta leguminosa. A caracterização genotípica (BOX+ERIC) mostra que, nas condições deste estudo, estes rizóbios apresentam $35 \%$ de similaridade com a estirpe recomendada.

\section{REFERÊNCIAS}

BARAIBAR A. et al. Symbiotic effectiveness and ecological characterization of indigenous Rhizobium loti populations In Uruguay. Pesquisa Agropecuária Brasileira, v.34, n.6, p.1011-1017, 1999. Disponível em: <http://www.scielo.br/pdf/ pab/v34n6/8402.pdf>. Acesso em: 03 out. 2009.

BARBERI, A. et al. Nodulação em leguminosas florestais em viveiros no sul de Minas Gerais. Cerne, v.4, n.1, p.145-153, 1998. Disponível em: <http://www.dcf.ufla.br/CERNE/revistav4n11998/art10.pdf>. Acesso em: 03 out. 2009.

BARRIENTOS, L. et al. Efectividad simbiótica de cepas naturalizadas de Mesorhizobium loti y Bradyrhizobium sp. (Lotus) en plantas de três espécies del gênero Lotus. Agricultura Técnica, v.62, n.2, p.226-236, 2002. Disponível em: <http://alerce.inia.cl/agriculturatec/Documentos/v.62(02)/ NR27812\%20p\%20226-236.pdf $>$. Acesso em: 17 mar. 2010.

BLUMENTHAL, M.J.; MCGRAW R.L. Lotus adaptation, use and management. In: BEUSELINCK, P.R. Trefoil: the science and technology of lotus. Madison: CSSA, 1999. V.28. p.266. (Special Publication n.28).

BORTHAKUR, D. et al. Identification of two classes of Rhizobium phaseoli genes required for melanin synthesis, one of which is required for nitrogen fixation and activates the 
transcription of the other. Molecular and General Genetics, v.207, p.155-160, 1987.

BROCKWELL, J. et al. Some symbiotic characteristics of rhizobia responsible for spontaneous, effective field nodulation of Lotus hispidus. Australian Journal of Experimental Agriculture and Animal Husbandry, v.6, p.365-370, 1966.

CARVALHO, F.G. Variabilidade de isolados de estirpes de Bradirhizobium spp. recomendadas para a cultura da soja. 2003. 77f. Tese (Doutorado em Ciência do Solo) - Curso de Pós-graduação em Ciência do Solo, Universidade Federal do Rio Grande do Sul, Porto Alegre, RS.

CHUEIRE, L.M.O. et al. Identificação das estirpes de Bradyrhizobium e Rhizobium utilizadas em inoculantes comerciais para as culturas da soja e do feijoeiro pela técnica de PCR com "primers" aleatórios ou específicos. Agricultura Tropical, v.4, p.80-95, 2000.

CUBO, M.T. et al. Melanin productions by Rhizobium strains. Applied and Environmental Microbiology, v.54, n.7, p.1812-1817, 1988.

de BRUIJN, F.J. Use of repetitive extragenic palindromic and enterobacterial repetitive intergenic consensus sequences and the polimerase chain reaction to fingerprint the genomes of Rhizobium meliloti isolates and other soil bacteria. Applied and Environmental Microbiology, v.58, p.2180-2187, 1992.

GRANGE, L. A análise polifásica na reclassificação filogenética de Rhizobium etli e o estudo da diversidade genética de isolados dos cerrados brasileiros. 2005. $153 \mathrm{f}$. Tese (Doutorado em Genética) - Departamento de genética, Setor de Ciências Biológicas, Universidade Federal do Paraná, Curitiba, PR.

GIONGO, A. et al. Genetic diversity and symbiotic efficiency of population of rhizobia of Phaseolus vulgaris L. in Brazil. Biology and Fertility of Soils, v.43, p.593-598, 2006.

IRISARRI, E. et al. Characterization of rhizobia nodulating Lotus subbiflorus from Uruguayan soils. Plant and Soil, v.180, p.39-47, 1996.

LABANDERA, C. Metodologías aplicadas a la evaluación de rhizobios para inoculantes para leguminosas forrajeras en Uruguay. Trabajos Técnicos. Departamento de Microbiología de Suelos, 2007. Disponível em: <http://www.chasque.net/ microlab/LMSCI/TraTe/metaplic.htm>. Acesso em: $12 \mathrm{fev}$. 2007.

MOSTASSO, L. et al. Selection of bean (Phaseolus vulgaris L.) rhizobial strains for the Brazilian Cerrados. Field Crops Research, v.73, p.121-132, 2002. Disponível em: <http:// dx.doi.org/10.1016/S0378-4290(01)00186-1. Acesso em: 03 out. 2009. doi:10.1016/S0378-4290(01)00186-1.
MUJICA M.M.; RUMI C.P. Effects of salinity on the germination of Lotus glaber Mill.(= Lotus tenuis Waldst. et Kit. ex Wild.). Lotus Newsletter, v.30, p.3-4, 1999. Disponível em: <http:// www.psu.missouri.edu/lnl/v30/Mujica.htm>. Acesso em: 03 out. 2009.

RICHARDSON, A. E. et al. Differentiation of Rhizobium strains using the polymerase chain reaction with random and directed primers. Soil Biology \& Biochemistry, v.27, p.515527, 1995. Disponível em: <http://dx.doi.org/10.1016/00380717(95)98626-Y>. Acesso em: 03 out. 2009. doi:10.1016/ 0038-0717(95)98626-Y.

SÁ, E.L.S. de. Diversidade fenotípica e genética de rizóbios isolados de feijoeiro (Phaseolus vulgaris) em solos ácidos de Cunha - SP. 2001. 109f. Tese (Doutorado em Ciência Energia Nuclear na Agricultura) - Centro de Energia Nuclear na Agricultura, Universidade de São Paulo, Piracicaba, SP.

SARRUGE, J.R. Soluções nutritivas. Summa Phitopathologica, v.1, n.3, p.231-234, 1975.

SCOTT, A.J.; KNOTT, M. A cluster analysis method for grouping means in the analysis of variance. Biometrics, v.30, p.507-512, 1974.

SHANNON, C.E.; WEAVER, W. The mathematical theory of communication. Bell Systems Technical Journal, v.27, p.379-423, 1948 .

TEDESCO, M.J. et al. Análise de solo, plantas e outros materiais. 2.ed. Porto Alegre: Departamento de Solos da UFRGS, 1995. 174p.

VERSALOVIC, J. et al. Genomic fingerprinting of bacteria using repetitive sequence-based polymerase chain reaction. Methods in Molecular and Cellular Biology, v.5, p.2540, 1994.

VIGNOLIO, O.R. et al. Flooding tolerance in five populations of Lotus glaber Mill. (Syn. Lotus tenuis Waldst. et. Kit.). Australian Journal of Agricultural Research, v.50, n.4, p.555-560, 1999. Disponível em: <http://www.publish.csiro.au/ paper/A98112.htm>. Acesso em: 03 out. 2009. doi:10.1071/ A98112.

VINCENT, J.M. A manual for the practical study of root nodule bacteria. Oxford: Blackwell Scientific, 1970. 200p. (IBP Handbook, 15).

WANG, T. et al. Diverse Mesorhizobium plurifarium populations native to Mexican soils. Archives of Microbiology, v.180, p.444-454, 2003. Disponível em: <http:/ /www.springerlink.com/content $/ 3451$ axjhye $1857 \mathrm{pl} /$. Acesso em: 03 out. 2009>. doi: 10.1007/s00203-003-0610-z. 